\title{
Research on Performance Evaluation of Human Resources Management in Public Sector
}

\author{
Yifang Wei \\ Nanyang Institute of Technology \\ Nanyang, Henan 473004, China
}

\begin{abstract}
Performance evaluation is one of the most important works in human resources management in public sector. In addition, performance appraisal system is a crucial evaluation criterion for organizations and employee contributions. In this paper, we analyzed the problems of human resources management performance assessment in public sector, such as lack of institutional support, immature evaluation system, lack of motivation, lack of flexibility salary system and other issues. These deficiencies seriously affected the efficiency of human resource management in the public sector. At the same time, the corresponding optimization measures and solutions are put forward, including establishing institutional foundation and optimizing social environment, improving human resources performance appraisal system, establishing a flexible compensation system and improving incentives, as well as applying performance management model based on big data.
\end{abstract}

Keywords-Human resources; Performance evaluation; Public sector; Management; Problems

\section{INTRODUCTION}

Public sector refers to the public authority which is based on the public interest for the purpose of social affairs management and services according to the law department of the organization. Performance evaluation is in accordance with certain procedures, methods and indicators to evaluate employee performance. It is to assess employee job performance, promotion and development, an important tool for various human resources activities and dismissal of employees distinguish levels. Also, by connecting performance and incentive compensation, it's working to achieve the purpose of the central part of employees [1]. Among the human resources performance management in public sector, performance evaluation is critical, and performance appraisal system also become the most important evaluation organizations and individuals to contribute [2]. In recent years, due to the rapid socio-economic development, it leads the human resources performance management revealed a number of flaws. Therefore, China's public sector gradually pay more attention on human resource performance management. What's more, they conduct a comprehensive thinking based on the reality of human resources performance management in the public sector of our country.

\section{Problems of Human Resources Management PERFORMANCE ASSESSMENT IN PUBLIC SECTOR}

\section{A. Lack of appropriate institutional foundation and social environment of human resource management}

As we all know, China's public sector human resource performance management is different from that of the company. When there is a problem of management, social and institutional environment cannot be made of the basis of effective protection of human resource performance management, then human resources performance management will have some flaws.

When the public sector in China conducts annual human resource performance appraisal, the leading departments do not attach great importance to the performance appraisal of each department. Based on the serious lack, there must be many efficiency indicators as strong support. Among them, the focus of public sector performance management is to maximize resources and strengthen the effect of resource operation and management. However, department heads are always not supported by basic data and are not equipped with adjustment strategies.

At the same time, the concept of "civil servants" still exists in the staff's mind, so the enthusiasm for performance appraisal is obviously not high, and there is no awareness of participation. The negative work consciousness of employees has a great impact on the work status of employees and even the improvement of performance in the future. The reduction of human resources performance will directly lead to the significance of reduction of human resources management in the public sector.

\section{B. The assessment system for human resources performance in the public sector is not sound}

The internal assessment of the public sector has the following six major problems: First, the assessment flows in the form, similar to the "transition", that is, many assessment contents have not been implemented; second, the assessment subject is single, and the 360-degree assessment often used in the enterprise is not used, especially It is the lack of assessment by the masses; the third is that the assessment indicators are not specific, the standards are not clear, and the differences in posts cannot be reflected, and there is a lack of refinement and quantitative indicators; fourth, the assessments are less and the proportion is lower; the fifth is that the assessment results are 
not in use. Lack of professional analysis, proposal, and followup of the assessment results; sixth, the target deviation of the assessment, the assessment of the staff is based on work performance or the value created by social public services, which is difficult to define.

When the human resources performance appraisal is carried out in the public sector, the analysis of the steps and processes is too cumbersome and there is no sound and complete assessment system leading to loopholes in the assessment. These assessment systems are clearly graded, delaying the transmission of information, and the human resources of the employees. The information of resource performance appraisal cannot be processed in time, which also greatly affects the results of human resources performance appraisal in China's public sector. The establishment of the assessment member group is also not manture. In the performance evaluation of human resources in the public sector, due to problems in the process of setting up the assessment team in the public sector, the staff of the assessment team were not careful enough and the assessment results were not objectively and fairly displayed to all employees, resulting in disputes and conflicts between employees and appraisers. As a result, the staff's low work mood and imperfect assessment system will directly affect the efficiency of human resources performance management in the public sector [3].

\section{The lack of incentive mechanism for human resources performance appraisal in the public sector}

The public sector plays an important role in national construction and social development. The human resource incentive mechanism is a human resource management norm with the principles of attraction, retention, incentive and development. For a long time, China's public sector has problems such as lack of incentives and lack of flexibility in the compensation system for human resources. These problems have seriously affected the efficiency of human resources management in the public sector. In the new era, improving the human resources incentive mechanism and deepening the reform of the personnel system have become issues that the public sector must pay attention to.

At the same time, the public sector lacks incentives based on individual potential and performance, and the disciplinary and restraint mechanisms of the sector are also weak. Therefore, many public sector employees try to enter the unit even for the permanent system of civil servants. However, in the absence of occupational risk and incentives, many people lack a sense of crisis and responsibility, which will inevitably affect the work of the public sector.

\section{Insufficient informationization of human resources performance appraisal in public sector}

At this stage, many complex reports do not run long in traditional systems, and there is a problem of timeout, which will increase the difficulty of system maintenance and operation, as well as cannot be applied in practice. Due to the large demand for reporting in the public sector, if the changes are relatively frequent, it is easy to increase the pressure on the information department and ultimately fail to respond properly.
In addition, the current report needs to be developed by programming, so the characteristics of reusability and flexibility are not obvious, and it will take a certain amount of manpower and material resources.

\section{OPTIMIZATION MEASURES AND COUNTERMEASURES FOR HUMAN RESOURCES MANAGEMENT PERFORMANCE APPRAISAL IN THE PUBLIC SECTOR}

\section{A. Establish institutional foundation and optimization of social environment}

We need to ensure the establishment of the institutional foundation of our country. The system is the basis of human resources performance management in China's public sector. Without the support of the system, human resource performance management is just on paper. China should carry out further institutional optimization on the basis of the original human resources performance appraisal management system, and clearly list and evaluate the human resources performance appraisal system involved in the public sector, as well as increase employee training. The importance of the human resources performance appraisal management system. Optimize the social environment. Before the development of China's public sector is not mature, we should deepen the institutional reform of China's public sector and optimize the social environment for human resources performance appraisal management.

\section{B. Improve the human resources performance appraisal system}

The public sector should refine and quantify the assessment indicators of the public sector, making it easy to measure and representative. The establishment of public sector assessment indicators should meet the job requirements of each position and effectively reflect the functions of this job. The public sector can learn from the relevant assessment mechanisms of enterprises and use scientific assessment methods to test employees. Moreover, in the assessment process, it is necessary to implement all aspects of the assessment, strengthen the analysis of the assessment results, propose improvement plans, and follow up the follow-up investigations.

The performance evaluation mechanism of hierarchical classification and the dynamic evaluation index database should be actively created. At the same time, the performance management data information base and the information data exchange platform should be established, so that the financial performance evaluation intermediary structure and experts can be realized. The library is fully improved and always subject to effective supervision by the staff. In addition, to ensure the effectiveness of the budget performance management work, the performance information and budget are organically combined to form a corresponding mechanism, and the performance information reporting system is improved, and the performance information feedback mechanism is strictly regulated. Based on this, it is also necessary to improve the performance information disclosure mechanism, to create a reward and punishment mechanism based on performance, and to pay attention to the effective application of performance evaluation results. Finally, the performance evaluation results will be the 
focus, while the departments will be appropriately adjusted and the expenditure structure will be fully optimized. The budget will be arranged reasonably, and the overall utilization rate of funds will be finally improved [4].

\section{Establish an flexible compensation system and improve incentives}

Payment system is not only the material basis of public sector staff motivation, but also the fundamental survival and development of staff. In the new era, rigid salary management system has been unable to meet the development requirements of the public sector. Therefore, on the basis of equal pay and on the principle of balance, our government, our government will establish the public sector and civil service pay system elasticity, giving public sector managers right to pay the deployment and management to an extent, linking the job performance of civil servants and bonuses, and other benefits with work, giving outstanding employees with additional incentives. At the same time, we need to give full consideration of duties on civil servants, the size of the responsibilities assumed by, the appropriate leadership positions and opened the non-leadership positions, the income gap between knowledge workers and the general staff, the implementation of multi-level incentives to ensure that the income of civil servants and their responsibilities and risk highly consistent. On this basis, we will improve the social security system, unarm the worries about the civil service, stimulate the civil servants in mental. Opinions as to broaden the channels of the unit; allows employees to participate in decision-making and management; create appropriate department management system; establish high-quality construction department of culture, which are in order to stimulate public servants belonging and identity [5].

\section{Apply performance management model based on big data}

The construction of data mining and business analytics platforms can provide the public sector with the services it needs to effectively improve performance management, from insight to execution. Specifically, it is based on the analysis of data information to timely discover the problem, and through use of targeted measures to correct the business, to observe the final correction effect to ensure that the problem can be handled and resolved, and at the same time, performance management. The application of the model can also give the public sector information system a certain help, which can be transformed from the provider of the information system into a supporter of decision-making, playing a more important role in decision-making of the public sector. In addition, in the public sector, there is a certain difference in the needs of data analysis at all levels of management. The leadership of the department mainly hopes to monitor the business status and equipment usage in real time. At the same time, it is hoped that the business intelligence platform can put data information in timely delivery, and through the data to analyze and predict the future development trend of the department, to help other leaders to adjust the development strategy [4]. Leaders of the department should obtain more accurate information reports in a timely manner, and the public sector should re-engineer the implementation process by fully optimizing the process of applying the information system. Therefore, we should pay attention to the basic role of data warehouse, in order to build a departmental decision support system, and further promote the digital construction of the department. The public sector data mining and application platform is based on the performance management cycle, using a variety of assessment methods to effectively assess and assess the performance of organizations and staff, and thus better performance target management and process management. Through this, we will realize the perfect connection between public sector strategy and performance management, rationally apply the process, and correctly guide the managers to continuously improve the internal operations of the public sector, so that the operation work is more standardized. As a result, the public sector's operational strategy and incentives will be more comprehensive. Similarly, it is possible to achieve the interconnection of action plans and regulatory indicators, and actively create a communication feedback mechanism that covers management to staff to ensure the effective implementation of plans and indicators. Finally, we should also thoroughly analyze operational efficiency and quality to achieve dynamic analysis and monitoring. In addition, we need to conduct a comprehensive analysis of the growth and lag points of the public sector, as well as provide in-depth knowledge of the resource allocation of the public sector. We will by then provide a strong guarantee for the rationality of resource allocation, save capital investment, comprehensively adjust and optimize performance appraisal content.

\section{CONCLUSION AND OUTLOOK}

The public sector is very important to all members of society, and therefore human resource performance management in the public sector is also particularly crucial. But in the current situation, there is a problem in China's public sector human resources performance appraisal. This paper presents the methods and countermeasures to solve these problems. It also analyzed China's current situation in the public sector. Only by optimizing the human resources performance appraisal of social context and establishing a good system based on a sound assessment of our system and our assessment criteria clarification, will our country make the public sector human resource performance management more convenient and effective, making our country the development of public utilities to the next level.

\section{REFERENCES}

[1] T. Kim and M. Holzer, Public Employees and Performance Appraisal: A Study of Antecedents to Employees' Perception of the Process, Review of Public Personnel Administration, First Published on October 5, 2014.

[2] Daley D M. Strategic human resources management [J]. Public Personnel Management, 2012: 120-125.

[3] Van Dooren, Wouter, Geert Bouckaert, and John Halligan. Performance management in the public sector. Routledge, 2015.

[4] Spekle R F, Verbeeten F H M. The use of performance measurement systems in the public sector: Effects on performance [J]. Management Accounting Research, 2014, 25(2): 131-146.

[5] Arnaboldi M, Lapsley I, Steccolini I. Performance management in the public sector: The ultimate challenge [J]. Financial Accountability \& Management, 2015, 31(1): 1-22.

[6] Bratton J, Gold J. Human resource management: theory and practice [M] Palgrave, 2017. 